
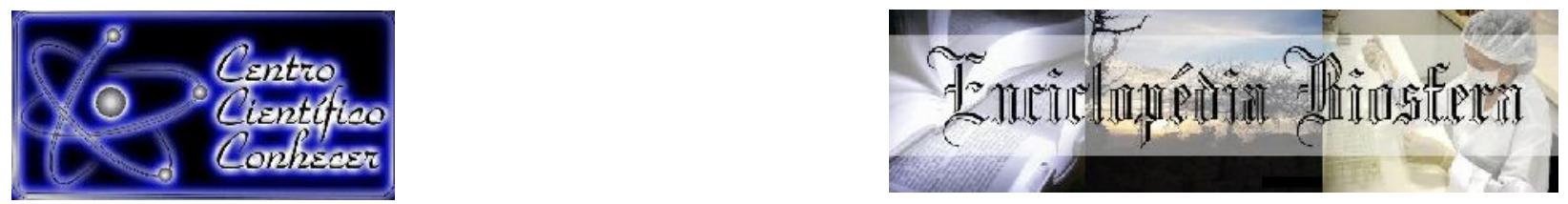

\title{
SAZONALIDADE, DISTRIBUIÇÃO DOS GÊNEROS, RIQUEZA, ABUNDÂNCIA DAS DIATOMÁCEAS EM RIOS URBANOS E AS INDICAÇÕES AMBIENTAIS. PARAGOMINAS, PARÁ (BRASIL)
}

Nayara do Socorro Nascimento Farias ${ }^{1}$; Ana Claudia de Sousa da Silva1; Liliane Ferreira do Rosário2; Antônio Pereira Júnior³

1 Engenheiras Ambientais. Universidade do Estado do Pará. 2 Doutoranda - UFPA-NAEA

${ }^{3}$ Mestre em Ciências Ambientais. Universidade do Estado do Pará. Laboratório de Qualidade Ambiental. E-mail: antonio.junior@uepa.br

Recebido em: 04/10/2019 - Aprovado em: 30/11/2019 - Publicado em: 15/12/2019 DOI: 10.18677/EnciBio_2019B51

\section{RESUMO}

O objetivo dessa pesquisa foi analisar a atuação da sazonalidade sobre a distribuição, riqueza e abundância sobre as diatomáceas, nos rios Prainha e Uraim, Paragominas - PA, períodos chuvoso e seco. O método utilizado foi o dedutivo, com pesquisa de natureza aplicada e procedimento experimental. A obtenção de dados foi efetuada em 12 amostragens, seis em cada período, em três pontos distintos dos daqueles rios. Os dados secundários foram obtidos a partir do levantamento de dados documentais em bases de pesquisas de livre acesso como Scientific Eletronic Library Online (SciELO), Coordenação de Pesquisa do Ensino Superior (CAPES), Web Science, cujo recorte temporal situou-se entre 2010 e 2019. Os dados obtidos indicaram que, no período chuvoso, o número de gêneros identificados em ambos os rios, foram similares ( $5=45,45 \%)$; no período seco, nove $(81,81 \%)$ foram encontrados no rio Prainha, e sete $(63,63 \%)$ no Rio Uraim; os valores para a riqueza, no rio Prainha variaram $\left(H^{\prime}=1,77\right.$ para $\left.H^{\prime}=2,13\right)$ do período chuvoso para o seco; e no Uraim $\left(H^{\prime}=1,89\right.$ para $\left.H^{\prime}=2,15\right)$; quanto a abundância, no período chuvoso, o gênero Navicula se caracterizou-se como a mais abundante $(57,1 \%)$ no primeiro rio, e pouco abundante (34,9\%). Já o período seco, no rio Prainha, o gênero Navicula sp $(41,6 \%)$, foi classificado como abundante; Aulacoseira sp $(31,7 \%)$ pouco abundante. No rio Uraim, obteve-se esse último gênero, com a mesma classificação $(39,5 \%)$. Dessa maneira, ficou claro que a sazonalidade é um fator atuante sobre as diatomáceas em rios urbanos.

PALAVRAS-CHAVE: Gêneros. Parâmetros de qualidade. Períodos 


\title{
SEASONALITY, GENDER DISTRIBUTION, RICHNESS, ABUNDANCE OF DIATOMS IN URBAN RIVERS AND ENVIRONMENTAL INDEX
}

\begin{abstract}
The objective of this research was to analyze the performance of seasonality on the distribution, richness and abundance of diatoms in the rivers Prainha and Uraim, Paragominas - PA, rainy and dry periods. The method used was deductive, with applied nature research and experimental procedure. Data were obtained in 12 samples, six in each period, in three different points from those of those rivers. Secondary data were obtained from the survey of documentary data in open access research databases such as Scientific Electronic Library Online (SciELO), Coordination of Higher Education Research (CAPES), Web Science, whose temporal cut was between 2010 and 2019. The data obtained indicated that, in the rainy period, the number of genera identified in both rivers was similar ( $5=45.45 \%)$; in the dry period, nine (81.81\%) were found in the first River, and seven (63.63\%) in the second River; the values for richness in the first River varied $\left(H^{\prime}=1.77\right.$ for $H^{\prime}=2.13$ ) from the rainy to the dry period; and in the second $\left(H^{\prime}=1.89\right.$ for $\left.H^{\prime}=2.15\right)$; as for abundance, in the rainy period, the genus Navicula was characterized as the most abundant $(57.1 \%)$ in the first river, and little abundant $(34.9 \%)$. The dry period, in the first, that genera (41.6\%), was classified as abundant; Aulacoseira sp (31.7\%) was not very abundant. In the second, the latter genus was obtained, with the same classification (39.5\%). Thus, it became clear that seasonality is an active factor on diatoms in urban rivers.
\end{abstract}

KEYWORDS: Genres. Quality parameters. Periods.

\section{INTRODUÇÃO}

O estudo de comunidades bióticas, distribuição, abundância de espécies em determinadas áreas de amostragem, são fatores importantes a serem considerados para indicar a qualidade da água. Nesse contexto, as diferentes comunidades biológicas têm sido usadas para avaliar e monitorar a qualidade da água doce. Entre eles, as diatomáceas são reconhecidas mundialmente como indicadores de poluição orgânica e eutrofização (CHELLAPPA et al.,2009; RANGEL et al., 2017).

Além de possuírem ciclo de vida curto e diversidade ao longo de todo o corpo hídrico, apresentam também sensibilidade a alterações e distúrbios ambientais nas características físico, química e biológica e, por isso, respondem rapidamente à estas condições $\mathrm{O}$ monitoramento de comunidades biológicas específicas podem funcionar como importante ferramenta para sinalizar alterações das condições limnológicas e hidrológicas (MORESCO et al., 2011; ALMEIDA; BICUDO, 2014).

Ademais, as diatomáceas são consideradas as mais bem-sucedidas espécies como indicadores de qualidade da água, por estar associadas à resposta a mudanças ambientais sutis, por sua sensibilidade e tolerância. Isso porque a variação destas comunidades de diatomáceas é manifestada espacialmente e temporalmente, baseados no clima, configurações geológicas e condições geomorfológicas, além dos fatores físico-químico da água (SALOMANI et al., 2011; RODRIGUES et al., 2015; NARDELI et al., 2016)

Junte-se a esses aspectos, o fato de que elas apresentam vantagens como: fazer parte do ciclo da energia em quase todos os ecossistemas lóticos que dispõem de grande parte dos alimentos e, portanto, mantêm os níveis tróficos mais elevados, para o estabelecimento do equilíbrio ecológico. Ainda mais, elas purificam as águas, absorvendo muitas impurezas, como nutrientes e metais pesados. Por isso elas 
respondem rapidamente à degradação da qualidade da água, muitas vezes mudando tanto na composição taxonômica quanto na biomassa, onde até mesmo uma leve contaminação ocorre (SANTANA et al., 2016).

Em áreas urbanas, as bacias hidrográficas se constituem como a mais adequada unidade de planejamento para o uso e exploração de recursos naturais, pois seus limites são imutáveis dentro do horizonte de planejamento urbano, facilitando o acompanhamento das alterações naturais ou introduzidas pelo homem (GARCIA et al., 2018) Assim, o disciplinamento do uso e da ocupação da bacia é o meio mais eficiente de controle dos recursos hídricos (PESSOA et al., 2017; QUEIROZ, OLIVEIRA, 2018).

O processo de intensificação da ocupação urbana, decorrente da necessidade de expansão das cidades, apresenta padrões de uso e ocupação do solo, muitas vezes, desordenados. Nesses casos, é comum observar que muitos rios tiveram os cursos alterados e áreas de várzeas aterradas e compactadas, o que provoca aumento das cheias urbanas, um dos graves problemas associados ao crescimento das cidades (ALVES et al., 2012; LEITE, CARRARA, 2013).

Portanto, o processo da expansão urbana ocorre sobre o território dos rios que atravessam ou marginam cidades e municípios brasileiros e, devido aos aspectos urbanos eles ficam ocultos na paisagem urbana. Após essa ocultação, eles passam a funcionar como receptores dos efluentes domésticos e industriais, muitas vezes chamados de valões por sua associação com o transporte de esgoto doméstico, ou ainda como meros corredores de drenagem

Com base nesses argumentos, torna-se importante a identificação das diatomáceas o que justifica esta pesquisa e incrementa a relevância dela, para o objetivo almejado que é a identificação, distribuição nos períodos chuvoso e seco, além do tipo de indicação ambiental nos rios Prainha e Uraim, Paragominas, Pará.

\section{MATERIAL E MÉTODOS}

\section{OS CORPOS HÍDRICOS ANALISADOS}

. Em relação ao rio Prainha também chamado de igarapé Paragominas, tratase se um rio que corta a área urbana do município e junto com o rio Uraim compõe a microbacia hidrográfica com o mesmo nome desse rio. Esse último é de extrema importância para o município de Paragominas, visto que ele auxilia no desenvolvimento dos serviços realizados de saneamento na cidade porque possibilita a retirada da água para o abastecimento público e o desaguamento dos efluentes tratados nas estações de origem domiciliar (PINTO et al., 2009; SANEPAR, 2014).

Os três pontos para a coleta da amostra de água e diatomáceas, distribuídos em $66 \mathrm{~m}$. Esse trecho do rio perpassa pela rua Bujaru, Bairro Promissão, Loteamento Promissão I, local com alta densidade populacional, sem saneamento básico, por isso, os efluentes desaguam nesse corpo hídrico.

O rio Uraim apresenta uma área de $4.9 \mathrm{~km}^{2}$, e ocupa uma área que corresponde a $21,75 \%$ do município de Paragominas. A vazão média anual de $268.423,35 \mathrm{~m} / \mathrm{h}$, é essencial para os serviços de saneamento da cidade, pois abriga o ponto de captação de água para abastecimento público. Ele é caracterizado como tributário de quinta ordem, da margem esquerda, do rio Gurupi (SANEPAR, 2014).

Neste rio, a amostragem foi efetuada em três pontos, distribuídos ao longo de $96 \mathrm{~m}$. Esse trecho perpassa pela rua Durval Nolasco, Bairro Promissão, Loteamento Promissão I, local de baixa densidade populacional, ausência de saneamento 
básico, as funções exercidas pelo corpo hídrico: balneabilidade, pesca, usos domésticos e comerciais como, por exemplo, lavagem de veículos automotores. Nos seis pontos de amostragem, segue-se a regularidade da margem direita dos rios, no sentido jusante para montante, portanto, contracorrente, em obediência ao Guia Nacional de Coleta e Preservação de Amostras (ANA, 2011).

\section{LOCALIZAÇÃO E DISTRIBUIÇÃO DOS PONTOS DE AMOSTRAGEM}

Os pontos planimétricos em função dos seis pontos de amostragens, três no rio Prainha: $\mathrm{P}-\mathrm{p}_{1}$ ( Figura 1a); $\mathrm{P}-\mathrm{p}_{2}$ (Figura 1b); $\mathrm{P}-\mathrm{p}_{3}$ (Figura 1c), e três no rio Uraim: U- $p_{1}$ (Figura 1d); U-p $p_{2}$ (Figura 1e); U-p $p_{3}$ (Figura 1f).

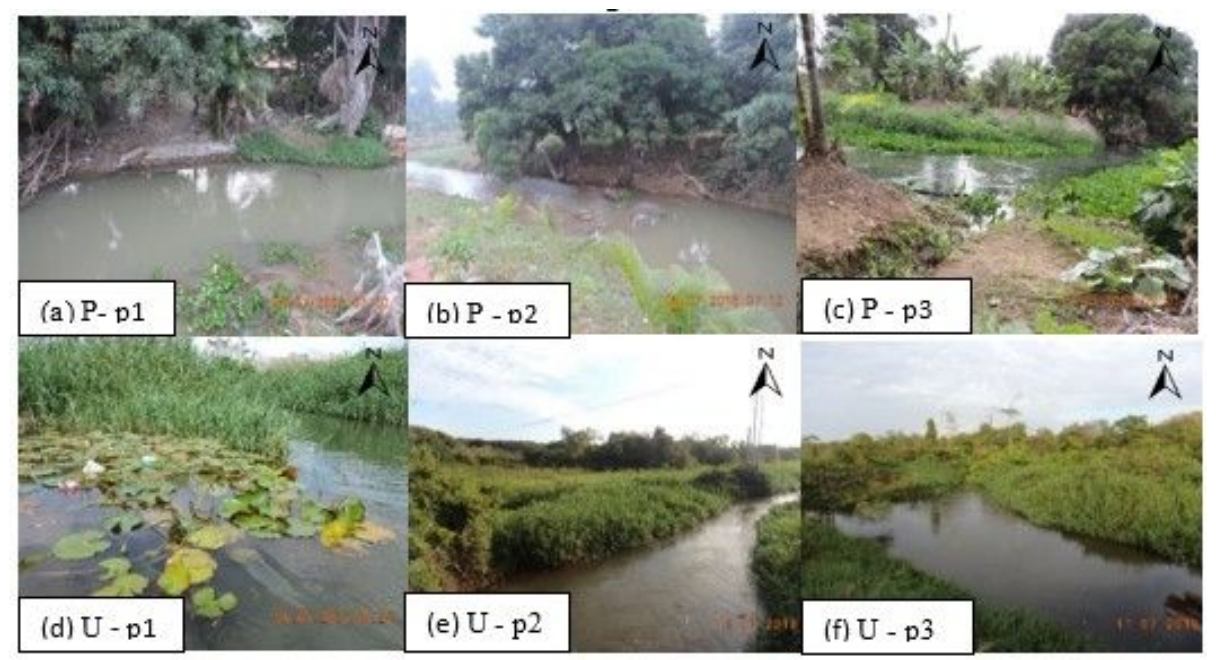

FIGURA 1 - Distribuição dos pontos de coleta no sentido montante/jusante no rio Uraim e Prainha. Paragominas - PA.

Fonte: autores (2018).

Com o uso do GPS, foram identificadas as posições planialtimétricas de cada um dos pontos de amostragem (QUADRO 1).

QUADRO 1 - Posicionamento planialtimétricos dos pontos de amostragem dos rios Prainha e Uraim. Paragominas - PA.

\begin{tabular}{|c|c|c|}
\hline PONTOS & LATITUDE & LONGITUDE \\
\hline$P-P_{1}$ & 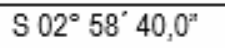 & W $047^{\circ} 21^{\prime} 09.6^{x}$ \\
\hline$P-P_{2}$ & $\mathrm{~S} 02^{\circ} 58^{\circ} 39,0^{\mathrm{t}}$ & W $047^{\circ} 21^{\circ} 10,5^{z}$ \\
\hline$P-P_{3}$ & $\mathrm{~S} 02^{\circ} 58^{\circ} 38,6^{\mathrm{a}}$ & W $047^{\circ} 21^{\circ} 11,2^{x}$ \\
\hline$U-P_{1}$ & $\mathrm{~S} 02^{\circ} 58^{\prime} 34,6^{\prime \prime}$ & W $047^{\circ} 21^{\prime} 214^{\pi}$ \\
\hline $\mathrm{U}-\mathrm{P}_{2}$ & $\mathrm{~S} 02^{\circ} 58^{\circ} 35,1^{\prime \prime}$ & W $047^{\circ} 21^{\prime} 22.6^{x}$ \\
\hline$U-P_{3}$ & $\mathrm{~S} 02^{\circ} 58^{\circ} 35,1^{z}$ & W $047^{\circ} 21^{\prime} 22.6^{x}$ \\
\hline
\end{tabular}

Legendas: P- p1: Prainha Ponto 1; P - p2: Prainha Ponto 2; P - p3: Prainha Ponto 3; U - p1: Uraim Ponto 1; U -p2: Uraim Ponto 2; $U$ - p3: Uraim Ponto 3.

Fonte: autores (2018). 


\section{COLETA DE DIATOMÁCEAS}

As coletas de diatomáceas epifíticas ocorreram no período chuvoso (maio) e no período seco (setembro), evitou-se a coleta logo após chuvas intensas com o objetivo de descartar perturbações na comunidade e alteração da turbidez. A técnica do substrato grosseiro obedeceu aos padrões estipulados por Lobo et al. (2016), como, por exemplo, seleção de galhos (Figura 2a), folhas longas (Figura 2b) e circulares (Figura 2c) que estejam cobertos com algas filamentosas que poderão gerar amostras compostas por uma mistura de diatomáceas.

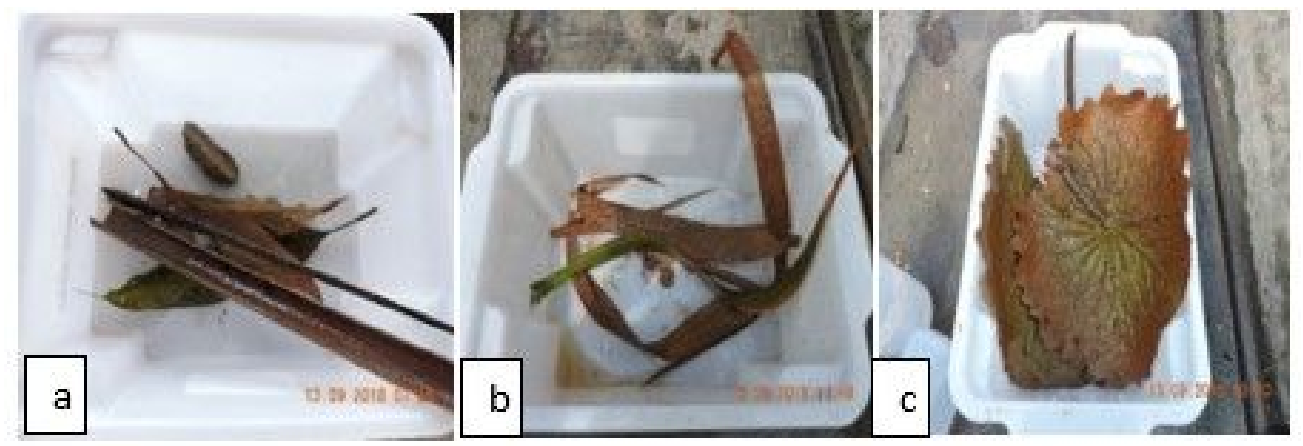

FIGURA 2 - Substratos grosseiros selecionados. Paragominas - PA. Fonte: autores (2018).

A retirada das diatomáceas dos substratos foram realizadas in situ (Figura 3), segundo o protocolo estabelecido pelo Guia ilustrado para sistemas lóticos subtropicais e temperados Brasileiros da Universidade de Santa Cruz do Sul (UNISC), de acordo com Lobo et al. (2016), com adaptações quanto a horários e característica dos corpos hídricos (Ex.: ausência de rochas) em alguns pontos de coletas.

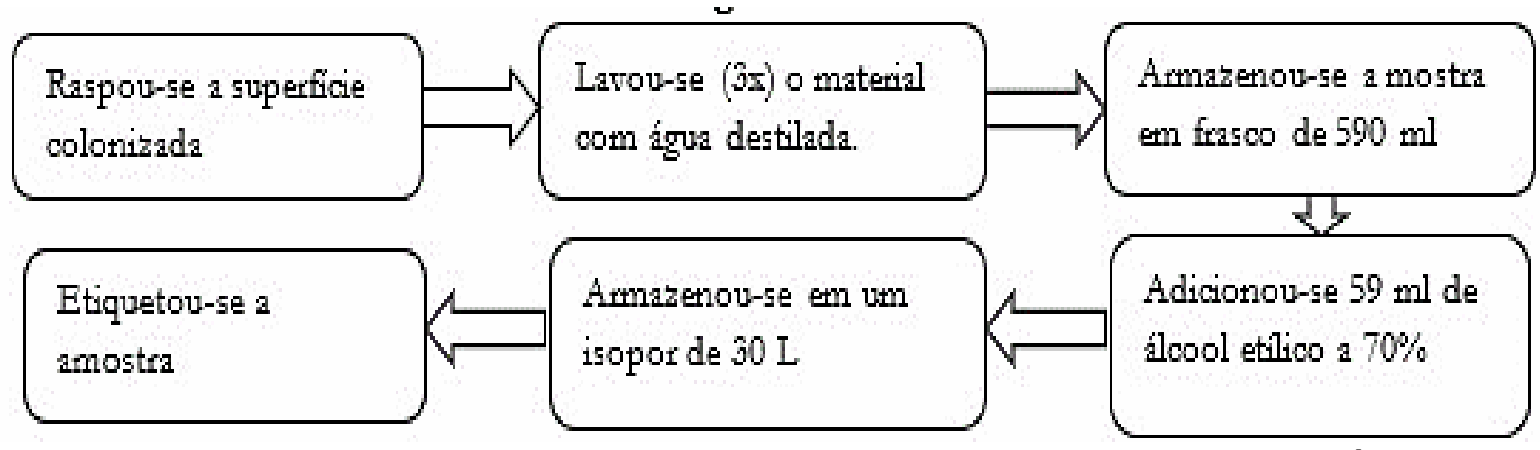

FIGURA 3 - Fluxograma quanto a procedimento para retirada das diatomáceas dos respectivos substratos. Fonte: autores (2018).

Este Guia também serviu como base no tratamento laboratorial das amostras e o procedimento de identificação das diatomáceas (Figura 4). 


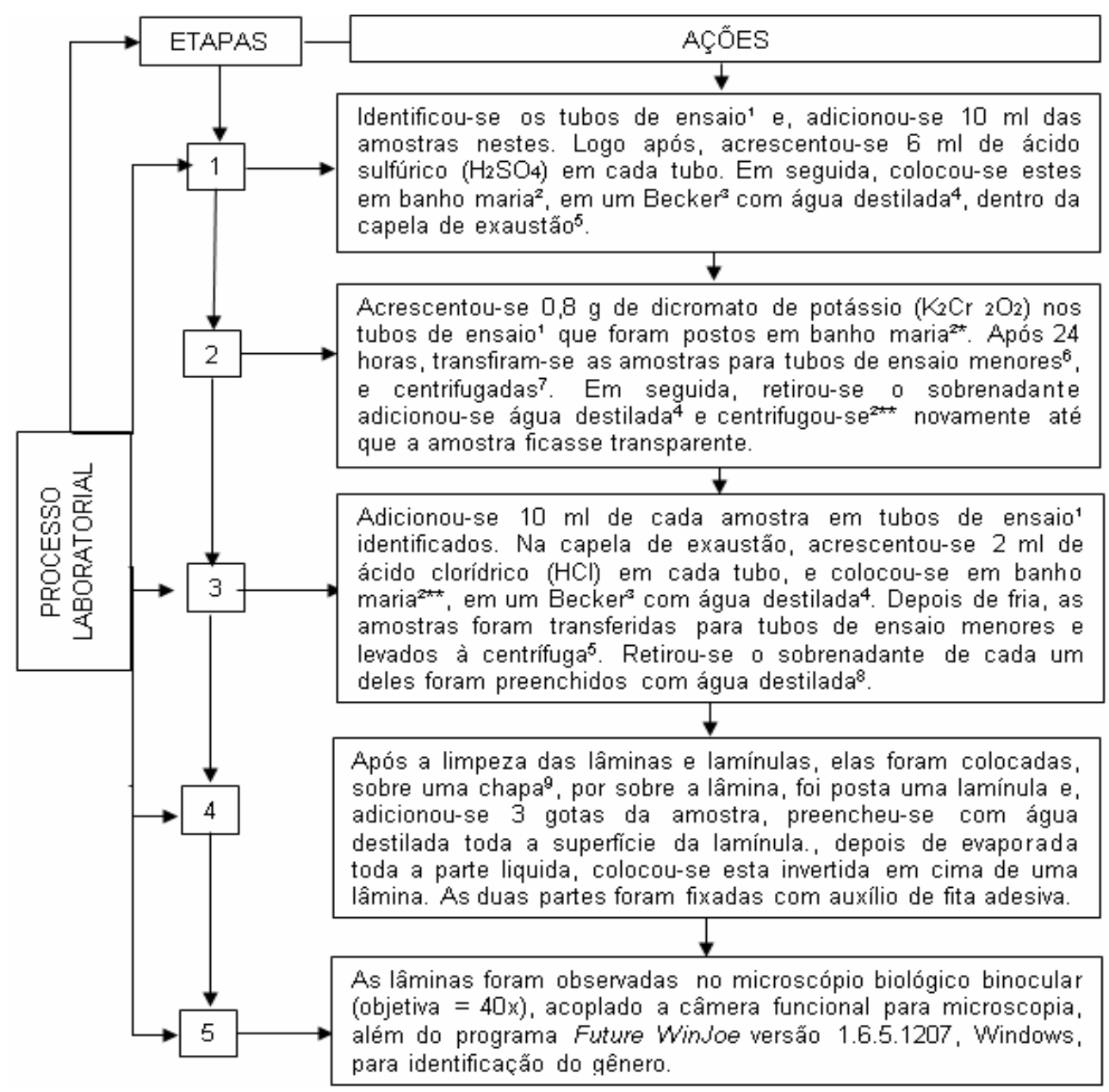

FIGURA 4 - Fluxograma do processo laboratorial das amostras e procedimento de identificação das diatomáceas. Paragominas - PA. Legendas: ${ }^{1}$ vidro de borossilicato; $\mathrm{V}=15 \mathrm{~mL}$ c./tampa de baquilite; ${ }^{2}$ 90 minutos; ${ }^{2 *} 60$ minutos; ${ }^{2 \star *} 30$ minutos; 3 vidro de borossilicato, $v=$ $250 \mathrm{~mL} ;{ }^{4} \mathrm{v}=90 \mathrm{~mL} ;{ }^{5}$ marca Quimis, $\mathrm{d}<1,2 \mathrm{~g} / \mathrm{cm}^{3} ;{ }^{6}$ vidro de borossilicato c./tampa de baquilite; $\mathrm{v}=10 \mathrm{~mL} ;{ }^{7}$ por 2 minutos a $3000 \mathrm{rpm} ;{ }^{8} \mathrm{v}=90 \mathrm{~mL} ;{ }^{9} 50^{\circ} \mathrm{C}$.

Fonte: autores (2018).

Para a análise dos dados biológicos (gênero), foram avaliados padrões de riqueza (Jackknife de primeira ordem. Equação 1); Índice de Diversidade (Equação 2); cálculo da Equitabilidade J (Shannon;Weaver. Equação 3); abundância relativa e dominância (Equação 4), conforme protocolos estabelecidos (Quadro 2). 
QUADRO 2 - Equaçoes utilizadas para os cálculos de quatro variáveis da dinâmica populacional.

\begin{tabular}{|c|c|c|}
\hline Análise para & Equações & Elementos componentes \\
\hline $\begin{array}{l}\text { Padrões de } \\
\text { riqueza }\end{array}$ & $E D=S_{o b s}+S 1\left(\frac{f-1}{f}\right)_{(1)}$ & $\begin{array}{l}\text { Soos = quantidade de gêneros observadas; } S 1=\text { quantidade } \\
\text { de gêneros que se encontra presente apenas em um } \\
\text { agrupamento; } f=\text { quantidade de agrupamento que contém } \\
\text { jesma de gêneros de um agrupamento. }\end{array}$ \\
\hline $\begin{array}{l}\text { Índice de } \\
\text { Shanonn- } \\
\text { Weaver }\end{array}$ & $H^{\prime}=-\sum p i * \log 2(p i)$ & $\begin{array}{l}p i=n i / N ; N i=\text { abundância relativa de cada gênero na } \\
\text { unidade amostral; } N=\text { abundância total }\end{array}$ \\
\hline Equitabilidade $\mathrm{J}^{1}$ & $J=\frac{H^{\prime}}{H \max ^{\prime}}$ & $\begin{array}{l}H^{f}=\text { Índice de Shannon-Weaver (1949): Hmax' = é dado pela } \\
\text { expressão } \boldsymbol{H} \boldsymbol{m a x} \boldsymbol{x}^{\prime}=\log \boldsymbol{s} ; \text { onde s é o número de } \\
\text { gêneros amostrados. }\end{array}$ \\
\hline $\begin{array}{l}\text { Determinação } \\
\text { da abundância } \\
\text { relativa e } \\
\text { dominância². }^{2}\end{array}$ & $A r=\frac{N}{n} * 100$ & $\begin{array}{l}\text { Ar }=\text { abundância }{ }^{3} \text { relativa expressa em percentagem }(\%) ; n= \\
\text { número de indivíduos de gêneros na amostra; } N=\text { número } \\
\text { total de indivíduos }\end{array}$ \\
\hline
\end{tabular}

1 - Quando os valores estiverem próximos de zero ou próximos de um, indicará uma a Equitabilidade.

2 - Lobo e Leighton (1986).

3 - Esse foi aplicado porque não há como inventariar a comunidade inteira dos dois rios analisados. A escala para a abundância adotada (SOUZA et al., 2009) apresenta as seguintes qualificações e quantificações valores: dominante (> $70 \%)$, abundante ( $\leq 70 \%$ e $>40 \%)$, pouco abundante $(\leq 40 \%$ e $>10 \%)$ e rara $(\leq$ 10\%).Fonte: autores (2018).

\section{RESULTADOS E DISCUSSÃO}

Os dados obtidos e analisados quanto identificação e caracterização das diatomáceas epifíticas que se desenvolveram em substratos naturais nos rios Prainha e Uraim nos períodos chuvoso e seco foram representados por um total 453 indivíduos pertencentes a 11 gêneros (Figura 5).

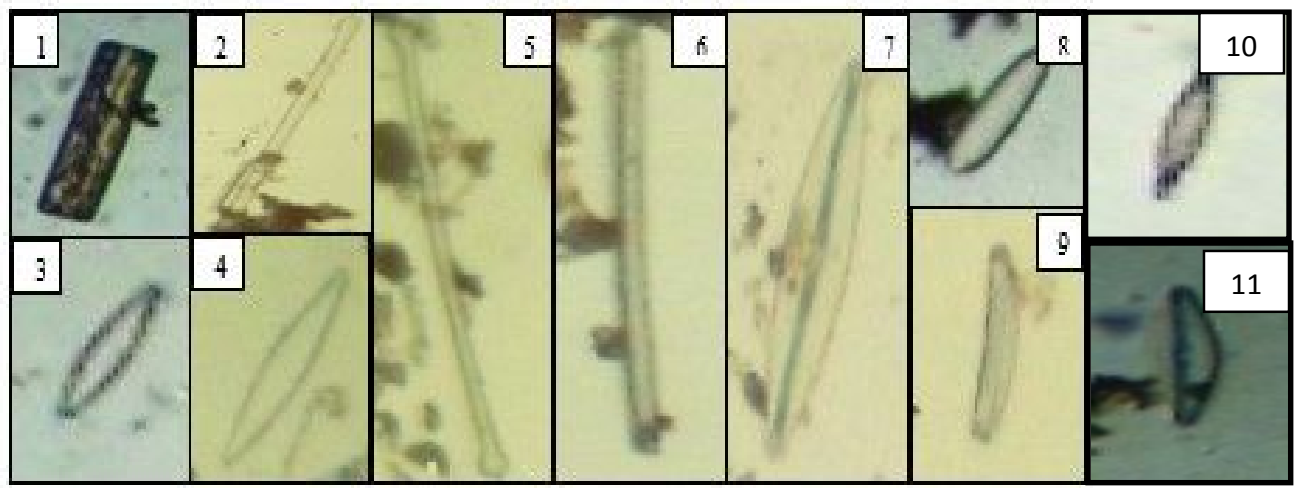

FIGURA 5 - Diatomáceas identificadas, quanto ao gênero, no rio Prainha e Uraim. Paragominas - PA.

Legendas - Fragilaria sp.; 2 - Aulacoseira sp.; 3 - Nitzschia sp.; 4 Gomphonema sp.; 5 - Eunotia sp.; 6- Ulnaria sp.; 7 - Navicula sp.; 8 Pinnularia sp.; 9 - Encyonema sp.;10- Ctenophora sp.; 11- Cymbella sp. Fonte: autores (2018).

Estes dados obtidos e analisados nos dois períodos sazonais (chuvoso e seco), indicaram que, deste total de gêneros (11): No Rio Prainha, foram identificados cinco $(55,55 \%)$ gêneros no período chuvoso; nove $(99,99 \%)$ no período 
seco. Em relação ao Rio Uraim, cinco (55,55\%) gêneros foram identificados no período chuvoso e sete $(77,77 \%)$ no período seco (Tabela 3$)$.

TABELA 3 - Gêneros identificados nos rios Prainha e Uraim nos dois períodos amostrados.

Paragominas - PA.

\begin{tabular}{|l|c|c|c|c|}
\hline & \multicolumn{2}{|c|}{ RIO PRAINHA } & \multicolumn{2}{c|}{ RIO URAIM } \\
\hline \multicolumn{1}{|c|}{ GÊNEROS } & PC & PS & PC & PS \\
\hline Aulacoseira sp & P & P & P & P \\
\hline Ctenophora sp & A & A & A & P \\
\hline Cymbella sp & A & A & A & P \\
\hline Encyonema sp & P & P & P & P \\
\hline Eunotia sp & A & P & A & P \\
\hline Fragilaria sp & P & P & P & P \\
\hline Gomphonema sp & A & P & A & A \\
\hline Navícula sp & P & P & P & P \\
\hline Nitzschia sp & P & P & A & A \\
\hline Pinnularia sp & A & P & P & A \\
\hline Uinaria sp & A & P & A & A \\
\hline
\end{tabular}

Legendas: PC - Período Chuvoso; PS - Período Seco, $\mathrm{P}$ - presente; A - ausente.

Fonte: autores (2018)

Quanto ao tipo de indicação ambiental, foi realizada uma pesquisa em Curitiba (PR), por Moresco e Rodrigues (2014), nesta, os autores concluíram que a Navícula sp é indicadora do crescimento urbano associado a condições de poluição orgânica. Quanto aos gêneros Aulacoseira $\mathrm{sp}$ e Fragilaria sp (diatomáceas pedunculadas), eles afirmaram que ambas são altamente sensíveis a ausência de nutrientes, ou seja, o estado trófico está alterado.

No que tange ao estado trófico, no estudo efetuado por Santos et al.(2017), naquela cidade, os pesquisadores concluíram que, caso haja a diminuição de nutrientes em um recurso hídrico, a comunidade de diatomáceas de alto perfil (Ex.: Aulacoseira sp e Fragilaria sp), tende a reduzir e a comunidades de baixo perfil (são mais sensíveis ao distúrbio físico) aumentar. Em Paragominas, verificou-se que, período chuvoso, em ambos os rios, houve ocorrência dos dois gêneros de diatomáceas identificadas em Curitiba, o que indica alteração no estado trófico nesses corpos hídricos.

Outro tipo de indicação ambiental, foi realizado pela pesquisa em um sistema trófico brasileiro, Rio Iguaçu (PR) por Silva et al. (2010), nela, os autores concluiram que esse gênero, quando presente indica que o corpo hídrico está entronizado. $\mathrm{Na}$ pesquisa realizada em Paragominas, esse mesmo gênero foi predominante no período seco, nas águas do rio Prainha, o que indica eutrofização no mesmo.

No que se refere a representatividade total de diatomáceas por gênero identificados nos dois rios, os dados obtidos indicaram uma tendência a variações (Figura 6). 


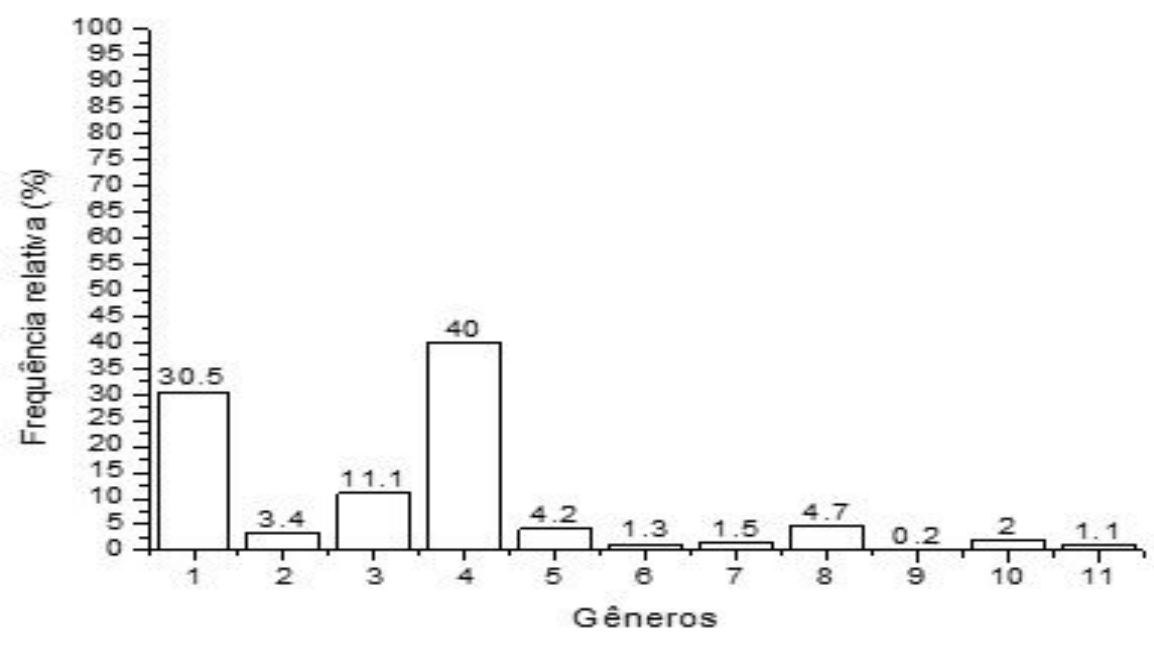

FIGURA 6 - Frequência relativa dos gêneros identificados nos dois rios. Paragominas- PA. Legendas: 1- Aulacoseira sp.; 2Encyonema sp.; 3- Fragilaria sp.; 4- Navícula sp.; 5- Nitzschia sp.; 6- Pinnularia sp; 7- Ctenophora sp.; 8- Cymbella sp.; 9Eunotia sp.; 10- Gomphonema sp.; 11- Ulnaria sp.

Fonte: autores (2018).

Essa variação pode estar relacionada ao fato que alguns gêneros são mais sensíveis às mudanças ambientais e outros mais tolerantes. Para Pereira Júnior et al. (2018), cada diatomácea tem limites de tolerância diferentes a mudanças ambientais normalmente associadas a condutividade, temperatura, concentração de nutrientes e contaminantes (orgânicos e inorgânicos).

Com relação à riqueza estimada de espécies (Jackknife de primeira ordem) a análise dos dados obtidos indicou uma tendência de variação quando comparados os valores entre os períodos chuvoso e seco dos rios Prainha $(S=5$ para $S=7)$ e Uraim $(S=4$ para $S=6)$, onde a tendência do maior valor para a riqueza de espécies, ocorreu, em ambos os rios, no período seco. Rodrigues et al., (2015) efetuaram um estudo sobre este mesmo tema, no município de São Luís (MA), e concluíram que um dos fatores que influenciam sobre a tendência de maior valor de riqueza de gêneros no período seco é a pouca turbulência e maior transparência das águas, visto que, no período chuvoso, os rios tem águas turvas e um maior valor e sólidos totais.

Quanto aos valores do índice de diversidade nos seis pontos de amostragem dos rios, houve uma tendência de diminuição da variação entre os períodos de coleta: no rio Prainha houve tendência de variação $\left(H^{\prime}=1,77\right.$ para $\left.H^{\prime}=2,13\right)$ do período chuvoso para o seco; e no Uraim $\left(H^{\prime}=1,89\right.$ para $\left.H^{\prime}=2,15\right)$. Logo, nota-se que apesar de pouca variação, a maior diversidade também corresponde ao período seco em ambos os rios (Figura 7). 


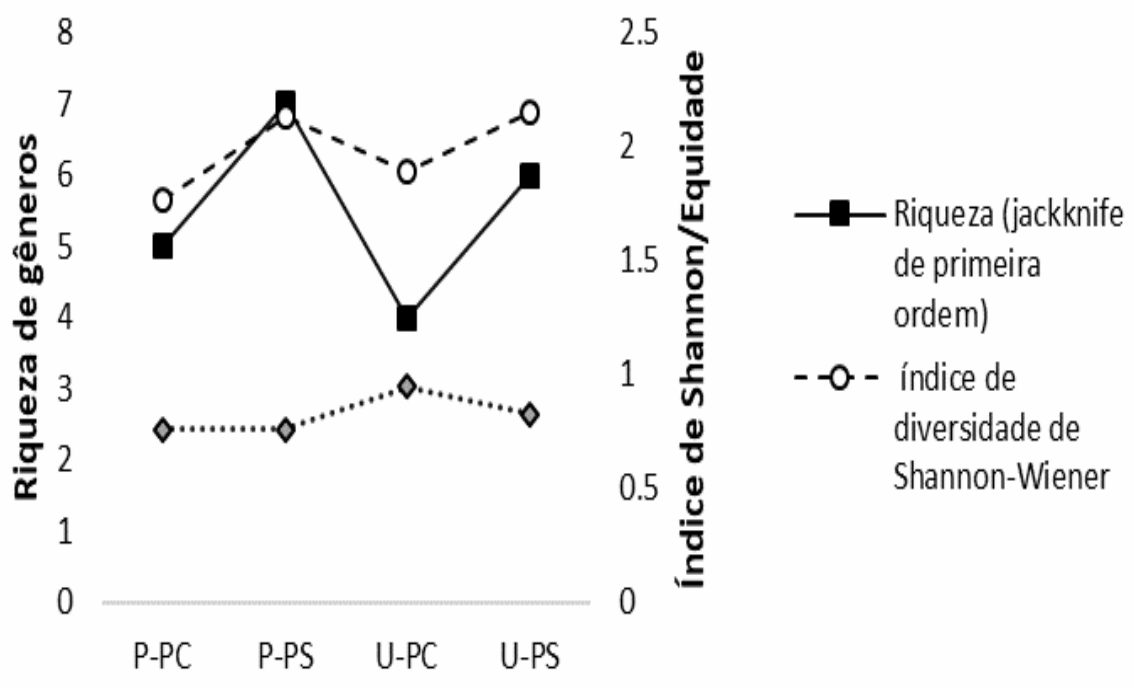

Períodos amostrais

FIGURA 7 - Valores para o Índice de Shanon e Weaver $\left(\mathrm{H}^{\prime}\right)$ dos gêneros, índice de diversidade e Equitabilidade $\mathrm{J}$ (EJ) das diatomáceas nos dois períodos de estudo em ambos os rios. Paragominas-PA.

Legendas: P- PC: Prainha Período Chuvoso; P-PS: Prainha Período Seco; U-PC: Uraim Período Chuvoso; U-PS: Uraim Período Seco. Fonte: autores (2018).

Quanto ao índice de diversidade, a análise dos dados indicou que há uma relação com os valores da riqueza de gênero. Então, conclui-se que os dois índices crescem ou decrescem juntos, ou seja, ele é diretamente proporcional à riqueza de espécies. Sobre esse tipo de riqueza, foi realizada uma pesquisa por Felisberto e Rodrigues (2012), em Diamante do Norte (PR). Os dados obtidos pelos autores apresentaram tendências muito semelhantes nos meses amostrais, o que corrobora com os dados obtidos na pesquisa realizada em Paragominas.

Já para a equitabilidade, os dados indicaram que em ambos os rios, há uma boa distribuição de gêneros nas amostras, porém no rio Uraim é mais alta $(0,13)$. Em relação a abundância relativa nos rios Prainha e Uraim (períodos chuvoso e seco), verificou-se que, no rio Prainha período chuvoso (Figura 8a), somente o gênero Navicula sp $(57,1 \%)$ categorizou-se como abundante, seguida do gênero Fragilaria sp $(25,4 \%)$ pouco abundante, e as demais Aulacoseira sp (9,5\%) Encyonema sp $(6,3 \%)$ Nitzschia sp $(1,7 \%)$ como raras. No período seco (Figura $8 b)$. nesse mesmo rio, a Navicula sp $(41,6 \%)$ foi a única novamente abundante dos nove gêneros identificados, Aulacoseira sp (31,7\%) como pouco abundante e as demais como raras. 

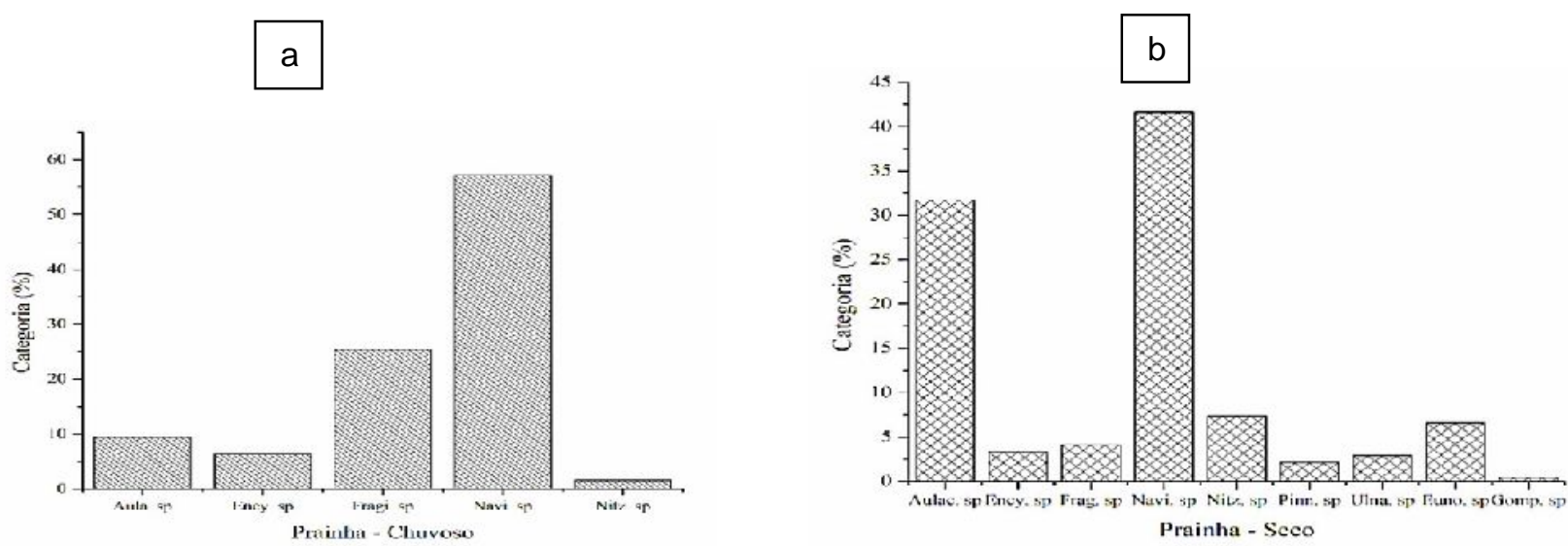

FIGURA 8 - a) Abundância de gêneros no rio Prainha no período chuvoso; b) no período seco Paragominas - PA.

Legendas: a) Aula. - Aulacoseira sp.; Ency. - Encyonema sp.; Frag. -Fragilaria sp.; Navi. Navicula sp.; Nitz. -Nitzchia sp.; b) Aula. - Aulacoseira sp.; Ency. - Encyonema sp.; Frag. Fragilaria sp.; Navi. - Navicula sp.; Nitz. -Nitzchia sp.; Pinn. -Pinnularia sp.; Ulna - Ulnaria sp.; Euno - Eunotia sp.; Gomp - Gomphonema sp.

Fonte: autores (2018).

O gênero Navicula sp o único abundante no rio prainha é conhecido mundialmente e considerado com grande abrangência ambiental, determinadas espécies desse gênero são estimadas como potentes indicadoras de impactos ambientais no ambiente aquático, principalmente em águas poluídas (RANGEL et al., 2017).

Para o rio Uraim no período chuvoso (Figura 9a) não houve nenhuma espécie abundante, porém, os gêneros Aulacoseira sp (26,1\%), Encyonema sp $(13,0 \%)$, Fragilaria sp, $(21,7 \%)$ e Navicula sp $(34,9 \%)$ foram categorizadas como "pouco abundante"; já Pinnularia sp (4,3\%) como "raro". No período seco (Figura 9b), os gêneros identificados Aulacoseira sp, (39,5\%), Fragilaria sp (15,3\%) e Navicula sp $(28,2 \%)$ foram consideradas como "pouco abundantes" e Encyonema sp, $(0,8 \%)$ Eunotia sp. (4,8\%) Ctenophora sp, (7,3\%) Cymbella sp (4,1\%) como "raros".
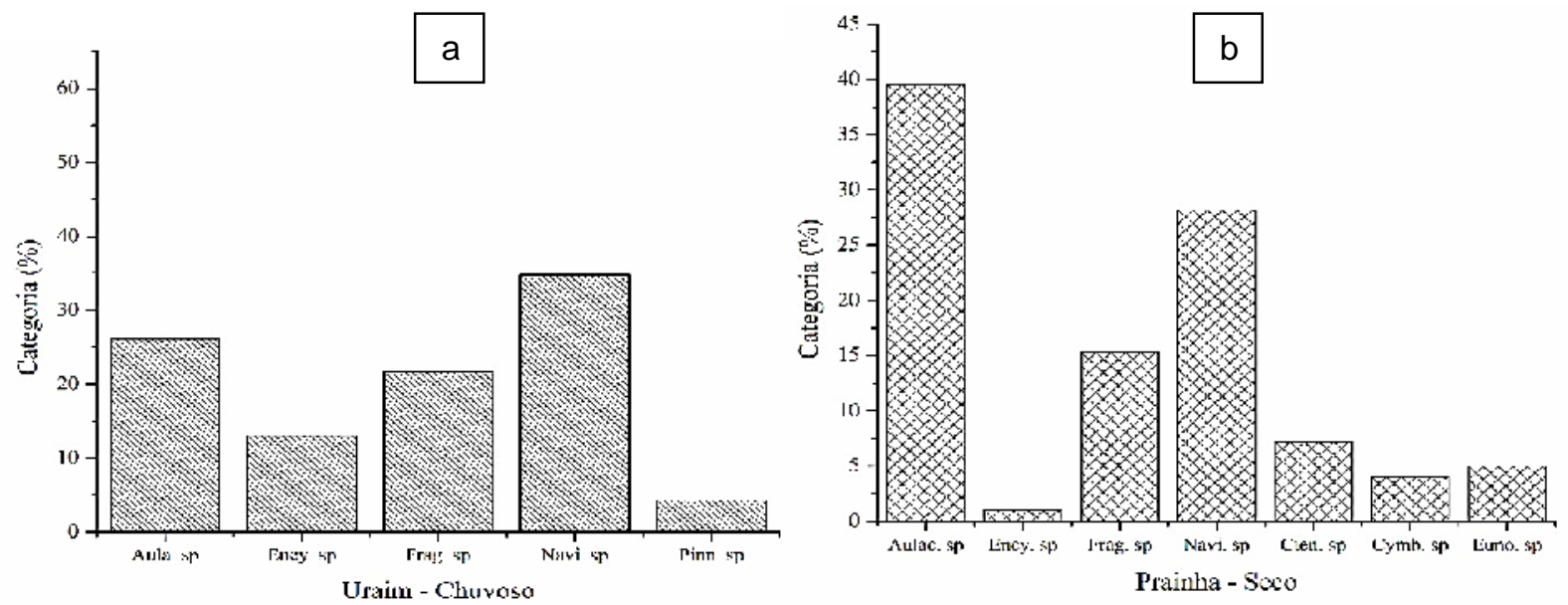

FIGURA 9 - a) Abundância de gêneros no rio Uraim no período chuvoso; b) no período seco. rio Uraim Paragominas-PA. Legendas: a) Aula. - Aulacoseira sp; Ency. - Encyonema sp.; Frag. -Fragilaria sp.; Navi. - Navicula sp.; Pinn. -Pinnularia sp.; b) Aula. - Aulacoseira sp; Ency. - Encyonema sp.; Frag. -Fragilaria sp.; Navi. - Navicula sp.; Cten - Ctenophora sp.; Cymb. - Cymbella sp.; Euno. - Eunotia sp.

Fonte: autores (2018). 
Acerca da abundância dos gêneros Aulacoseira sp e Navicula sp, Monteiro et al. (2009), realizaram pesquisas na Bacia do Rio Guamá e concluiram que entre os 29 gêneros encontrados, havia cinco do segundo gênero e do primeiro, participou da composição da categoria "dominante". Os dados obtidos em Paragominas indicaram que o primeiro gênero pertence a categoria "abundante", e o segundo, "pouco abundante". Isso pode ter ocorrido por fatores como a intensidade e o volume da chuva, porem tal mensuração não foi objeto dessa pesquisa.

\section{CONCLUSÃO}

A sazonalidade interfere na distribuição, riqueza e abundância das diatomáceas. Quanto a presença de diatomáceas no rio Prainha e Uraim foi efetiva. No primeiro, a maior representatividade delas ocorreu no período seco. No período chuvoso, esta representatividade diminui em ambos.

Logo, a presença de diatomáceas nos dois corpos hídricos analisados, ambos possuem indivíduos representativos, com maior frequência no rio Prainha, no período seco, exatamente onde houve maiores concentrações de fosforo total e presença de um gênero que é altamente sensível a ausência de nutrientes, embora no rio Uraim também tenha apresentado uma frequência de indivíduos. No período chuvoso, a frequência das diatomáceas diminuem em ambos os rios. Quanto a ausência das diatomáceas no período seco, poucos gêneros estiveram ausentes, enquanto, no período chuvoso, o número de gêneros ausentes foi maior em ambos os rios.

\section{REFERÊNCIAS}

ALMEIDA, P. D.; BICUDO, D. C. Diatomáceas planctônicas e de sedimento superficial em represas de abastecimento da Região Metropolitana de São Paulo, SP, Sudeste do Brasil, Hoehnea, v. 41, n. 2, p. 187-207, 2014. Disponível em: <http://www.scielo.br/scielo.php?pid=S2236-

$89062014000200004 \&$ script=sci_abstract\&tlng=pt.>

DOI: http://dx.doi.org/10.1590/S2236-89062014000200004.

ALVES, I. C. C.; EL-ROBRINI. M.; SANTOS, M. L. S.; MONTEIRO, S. M.; BARBOSA, L. P. F. et al. Qualidade das águas superficiais e avaliação do estado trófico do Rio Arari (Ilha do Marajó, norte do Brasil). Acta Amazonica, Manaus, v. 42, n. 1, p. 115-124, mar. 2012. Disponível em: http://www.scielo.br/scielo.php?script=sci_arttext\&pid=S0044-59672012000100014. DOI: http://dx.doi.org/10.1590/S0044-59672012000100014

ANA. Guia Nacional de Coleta e Preservação de Amostras. Brasília, Agência Nacional de Águas, n.2, 2011. Disponivel em: http://arquivos.ana.gov.br/institucional/sge/CEDOC/Catalogo/2012/GuiaNacionalDeC oleta.pdf

CHELLAPPA, N. T.; CÂMARA, F. R. A.; ROCHA, O. Phytoplankton community: indicator of water quality in the Armando Ribeiro Gonçalves Reservoir and Pataxó Channel, Rio Grande do Norte, Brazil, Brazilian Journal of Biology., v. 69, n. 2, p. 241-251, $2009 . \quad$ Disponível em: http://www.scielo.br/scielo.php?script=sci_arttext\&pid=S1519-69842009000200003 DOI http://dx.doi.org/10.1590/S1519-69842009000200003 
FELISBERTO, S. A.; RODRIGUES, L. Dinâmica sucessional de comunidade de algas perifíticas em um ecossistema lótico subtropical, Rodriguésia, v. 63, n. 2, p. 463-473, 2012. Disponível em: http://rodriguesiaseer.jbrj.gov.br/index.php/rodriguesia/article/view/266/178.

GARCIA, J. M., MANTOVANI, P.; GOMES, R.C.; LONGO, R.M.; DAMAMBORO, A.C.; et al.; Degradação ambiental e qualidade da água em nascentes de rios urbanos. Sociedade e Natureza, Uberlândia, v. 30, n. 1, p. 228-254, jan./abr. 2018. Disponível em: http://www.seer.ufu.br/index.php/sociedadenatureza/article/view/38336/pdf. DOI: http://dx.doi.org/10.14393/SN-v30n1-2018-10

LEITE, L. A. R.; CARRARA, J. A. Influência da mata ciliar na estrutura e composição da ictiofauna em trechos do córrego Barreirinho no município de ArealvaSP. Ensaios e Ciência: C. Biológicas, Agrárias e da Saúde, v. 17, n. 6, p. 47-62, dez. 2013. Disponivel em: https://revista.pgsskroton.com/index.php/ensaioeciencia. Acesso em 20 nov. 2018.

LOBO, E. A; HEINRICH. C. G.; SCHUCH, M.; DUPONT, A.; COSTA, A. B. et al. Índice Trófico de Qualidade $\mathrm{Da}$ Água ilustrado para sistemas lóticos subtropicais e temperados Brasileiros da Universidade de Santa Cruz do Sul. Santa Cruz do Sul, Universidade de Santa Cruz do Sul. 2016. Disponível em: http://repositorio.unisc.br:8080/jspui/bitstream/11624/1767/1/\%C3\%8Dndice\%20tr\% C3\%B3fico\%20de\%20qualidade\%20da\%20\%C3\%A1gua.pdf

LOBO, E.; LEIGHTON, G. Estruturas de las fitocenosis planctônicas de los sistemas de desembocaduras de rios y esteros de la zona central do Chile. Revista de Biologia Marinha, n. 1, v.22, p. 143-170, 1986. Disponível em: https://revbiolmar.uv.cl/escaneados/221-1.pdf

MONTEIRO, M. D. R.; MELO, N. F. A.; ALVES, M. A. M. S.; PAIVA, R. S. Composição e distribuição do microfitoplâncton do rio Guamá no trecho entre Belém e São Miguel do Guamá, Pará, Brasil. Boletim Do Museu Paraense Emilio Goeldi, v. 4, n. 3. P. $341-351$, 2009. Disponível em: http://scielo.iec.gov.br/pdf/bmpegcn/v4n3/v4n3a05.pdf.

MORESCO, C.; TREMARIN, P. I.; LUDWIG, T. A. V.; RODRIGUES, L. Diatomáceas perifíticas abundantes em três córregos com diferentes ações antrópicas em Maringá, PR, Brasil, Revista Brasileira de Botânica., v. 34, n. 3, p. 359-373, 2011. Disponível em: <http://www.scielo.br/scielo.php?script=sci_abstract\&pid=S0100$84042011000300010 \& \operatorname{lng}=e n \& n r m=i s o \& t \operatorname{lng}=$ pt. $>$ DOI:

http://dx.doi.org/10.1590/S0100-84042011000300010.

MORESCO, C.; RODRIGUES, L. Periphytic diatom as bioindicators in urban and rural streams, Acta Scientiarum, v. 36, n. 1, p. 67-78, 2014. Disponível em: http://periodicos.uem.br/ojs/index.php/ActaSciBiolSci/article/view/18175. DOI: https://doi.org/10.4025/actascibiolsci.v36i1.18175 
NARDELLI, M. S.; BUENO, N. C.; LUDWIIG, T. A. V.; GUIMARÃAES, A. T. B. Structure and dynamics of the planktonic diatom community in the Iguassu River, Paraná State, Brazil, Brazilian Journal of Biology, São Carlos, v. 76, n. 2, p. 374386, mai. 2016. Disponível em: http://dx.doi.org/10.1590/1519-6984.16114

DOI: http://dx.doi.org/10.1590/1519-6984.16114

PEREIRA JÚNIOR, A.; HOLANDA, L. B.; SILVA, A. C. S.; FARIAS, N.; MOURA, A. J. S. et al. As diatomáceas como indicadoras da qualidade da água em rios Urbanos. Multidisciplinary Reviews, v. 1 , set. 2018. Disponível em: https://docs.wixstatic.com/ugd/404990_cecde697ff484c02bfeb5426760a6624.pdf DOI: https://doi.org/10.29327/multi.2018012

PESSOA, E. K. R.;LIMA, P. L. S. C.; NASCIMENTO, W. S.; NAITHRIRITHI, S. C.CHEPALLA, N. T. Variações temporais dos parâmetros limnológicos, os grupos frequentes e índices biológicos da comunidade fitoplanctônica do açude Santa Cruz, Rio Grande do Norte, Brasil. Biota Amazônia, Macapá, v. 7, n. 2, p. 59-64, ago. 2017. Disponível em: https://periodicos.unifap.br/index.php/biota/article/view/2871 DOI: http://dx.doi.org./10.18561/2179-5746/biotaamazonia.v7n2p59-64

PINTO, A.; AMARAL, P.; SOUZA JÚNIOR, C.; VERÍSSIMO, A.; SALOMÃO, R. et al. Diagnóstico Socioeconômico e Florestal do município de Paragominas. Relatório Técnico. Belém: Instituto do Homem e Meio Ambiente da Amazônia Imazon, 2009. Disponível em: < http://imazon.org.br/PDFimazon/Portugues /outros/iagnostico-socioeconomico-e-florestal-do.pdf>.

QUEIROZ, T. M.; OLIVEIRA, L. C. P. Qualidade da água em comunidades quilombolas do Vão Grande, município de Barra do Bugres (MT). Engenharia Sanitária e Ambiental, Rio de Janeiro, v. 23, n. 1, p. 173-180, mai.2018. Disponivel em: http://www.scielo.br/scielo.php?pid=S1413$41522018000100173 \&$ script=sci_abstract\&tlng=pt.

DOI: http://dx.doi.org/10.1590/s1413-41522018166375.

RANGEL, A. J.; LUCAS, F. H. R.; CAVALCANTE, F. C.; NASCIMENTO, K. C. C.; OLIVEIRA, E. L. C., et al. Comunidade fitoplanctônica como discriminador ambiental em um trecho do rio salgado, semiárido nordestino. Cadernos de Cultura e Ciência, v. 15, n. 2, p. 29-41, 2017. Disponivel em: $<$ http://periodicos.urca.br/ojs/index.php/cadernos/article/view/1146/pdf>.

RODRIGUES, E. H. C. BARRETO, L. N.; FERREIRA-CORREIA, M. M.; SILVA, M. R. C. Variação temporal do fitoplâncton em um rio tropical pré-amazônico (Rio Pindaré, Maranhão, Brasil). Ciência e Natura, v. 37, n. 2, 2015. Disponível em: https://periodicos.ufsm.br/cienciaenatura. DOI: 10.5902/2179460X14855

SALOMANI, S. E. ROCHA, O.; HERMANY, G.; LOBO, E. A. Application of water quality biological indices using diatoms as bioindicators in the Gravataí river, RS, Brazil. Brazilian Journal of Biology, v. 71, n. 4, p. 949-959, 2011. Disponível em: $<$ http://www.scielo.br/scielo.php?script=sci_arttext\&pid=S1519-

69842011000500015.> DOI: http://dx.doi.org/10.1590/S1519-69842011000500015 
SANEPAR. AGÊNCIA DE SANEAMENTO DE PARAGOMINAS. Bacia do Uraim. 2014. Disponível em: <http://saneparagominas.com.br/agua/bacia_uraim/>. Acesso em: 28 fev. 2018.

SANTANA, L. M.; MORAES, M. E. B.; SILVA, D. M. L.; FERRAGUT, C. Spatial and temporal variation of phytoplankton in a tropical eutrophic river. Brazilian Journal of Biology,v. 76, n. 3, p. 600-610, 2016. Disponível em: $<$ http://www.scielo.br/scielo.php?script=sci_arttext\&pid=S1519-

69842016000300600 >. DOI: http://dx.doi.org/10.1590/1519-6984.18914

SANTOS, E. M.; SANTOS, F. A. A.; GOMES, M.V. C. N.; SANTOS, V. G.; NEVES, R. R. Análise Espacial das Ações do Programa "Municípios Verdes": Estudo de Caso no Município de Paragominas-PA. Revista Brasileira de Gestão Ambiental, v. 11, n. $1, \quad$ p. $21 \quad-\quad 35, \quad 2017 . \quad$ Disponível em: https://gvaa.com.br/revista/index.php/RBGA/article/view/4691. DOI: https://doi.org/10.18378/rbga.v11i1.4691

SILVA, A. M.; LUDWIG, T. A V.; TREMARIN, P. I.; VERCELLINO, I. S. Diatomáceas perifíticas em um sistema eutrófico brasileiro (Reservatório do Iraí, estado do Paraná). Acta Botanica Brasilis, v. 24, n. 4, p. 997 - 2010. Disponível em: http://www.scielo.br/scielo.php?script=sci_arttext\&pid=S0102-

33062010000400015\&lng=pt\&tlng=pt. $\quad$ DOI: http://dx.doi.org/10.1590/S010233062010000400015 